\title{
Study of the Freezing Temperature of Glutaric Acid as a New Reference Material in Thermometry
}

\author{
M.M. Halawa and Y.A. AbdelAziz
}

National Institute For Standards, Giza, Egypt

\begin{abstract}
The purification of Glutaric acid was carried out by zone melting technique. A study of freezing behavior of Glutaric acid $99.965 \%$ has been carried out by using Copper/Copper-Nickel thermocouple (type-T) which was calibrated by comparison against standard platinum resistance thermometer (SPRT) at the national institute of measurement (IMGC-Italy). The average value of the freezing point is found to be $97.18 \pm 0.28^{\circ} \mathrm{C}$. A laboratory technique for purification of Glutaric acid to be used as a reference material for thermometric work is also described. In this paper the results for the realization of Glutaric acid after and before purification are reported.
\end{abstract}




\section{Introduction:}

The freezing point of Glutaric acid is providing a secondary reference on the International Temperature Scale of 1990, hence it will be intermediate between the melting temperature of Gallium $\left(29.764^{\circ} \mathrm{C}\right)$ and the freezing point of Indium $\left(156.5985^{\circ} \mathrm{C}\right)$.

The purification of Glutaric acid was carried out by zone melting technique, which applied for organic compounds because of its simplicity and effectiveness in preparing high purity standards material rich up to $99.99 \%$.

\section{Experimental work:}

\subsection{Purification of Glutaric acid by zone refining technique:}

A Desaga macro-zone refining apparatus model [136000] was used with its ready made Desaga tubes. The details of the apparatus and technique are described in previous article [3]. The runs were repeated three times i.e. 36 zone refinements were carried out. When the runs were completed and the apparatus was switched off, the tube was allowed to cool out side of the apparatus and was cut into three sections of equal portions. The middle section was used for filling the cell since it is considered to be the purest one[4,5].

\subsection{Filling of the Glutaric acid cell:}

The freezing point cells used in the present work are made of Teflon due to its very high chemical stability. It is also flexible enough to permit the expansion of Glutaric acid. The dimensions of the cell are shown in Fig. (1).

The cell was cleaned in the following manner; initially washed with soap followed by ultrasonic cleaning with distilled water and soap bath for two hours, distilled water for two hours, then finally with acetone and rinsing with ethyl alcohol and distilled water. The clean cell was filled with approximately $250 \mathrm{gm}$ of pure Glutaric acid in pure Argon atmosphere, then sealed with epoxy.

\subsection{Realization of Glutaric acid freezing point:}

The Glutaric acid cell was immersed in a temperature controlled oven whose temperature was kept at $100.5^{\circ} \mathrm{C}$ for two hours. Melting of the sample was followed by the temperature indicated by the thermocouple, which was inserted into the cell. After melting, the cell was transferred to the oil bath whose temperature was kept at one degree below the melting point of Glutaric acid. When the Glutaric acid has cooled to a temperature near the freezing point it started supercooling. A precooled glass rod was inserted into the thermometer 
well to induce the Glutaric acid to freezing around the thermometer well .

Measurement of the EMF generated by thermocouple was measured by Guildline digital nanovoltmeter (DVM) model 4880- each five minute during the freezing plateau. Thermocouple type-T was used and nanovoltmeter with precision $0.01 \mu \mathrm{V}$.

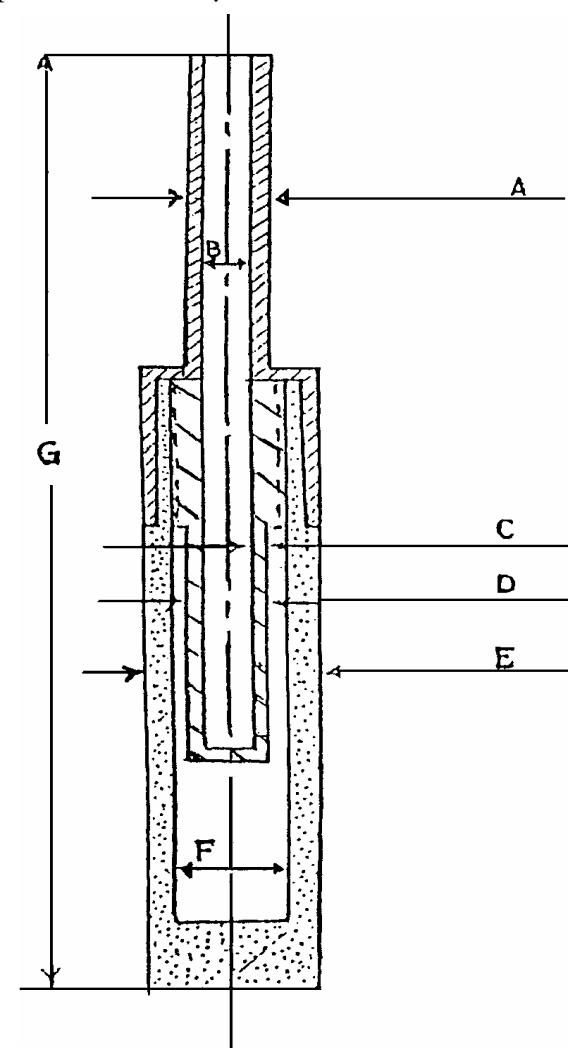

\begin{tabular}{|c|c|c|}
\hline Symbol & Large cell & Small cell \\
\hline $\mathrm{A}$ & $1.10 \mathrm{~mm}$ & $0.91 \mathrm{~mm}$ \\
$\mathrm{~B}$ & $0.80 \mathrm{~mm}$ & $0.48 \mathrm{~mm}$ \\
$\mathrm{C}$ & $0.19 \mathrm{~mm}$ & $0.21 \mathrm{~mm}$ \\
$\mathrm{D}$ & $1.20 \mathrm{~mm}$ & $1.0 \mathrm{~mm}$ \\
$\mathrm{E}$ & $4.22 \mathrm{~mm}$ & $2.40 \mathrm{~mm}$ \\
$\mathrm{~F}$ & $2.94 \mathrm{~mm}$ & $1.50 \mathrm{~mm}$ \\
$\mathrm{G}$ & $22.00 \mathrm{~mm}$ & $15.3 \mathrm{~mm}$ \\
\hline
\end{tabular}

Fig. (1): Design of Glutaric acid cell.

\subsection{Determination of Glutaric acid Purity by Cryoscopic Technique:}

The factors affecting the freezing temperature of the acid are the gas pressure above the molten acid, the impurity content, and the water vapour content.

Schwab and Wichers[6] in their study on the freezing temperature of the Glutaric acid have evaluated the effect of impurities on the freezing temperature. Based on these results it was possible to evaluate the cryoscopic constant (A) for Glutaric acid as equal to $1.8138 \% \mathrm{~K}^{-1}$.

The purity of the acid can be evaluated once its freezing temperature has been determined, from Raoult's law 


$$
\mathrm{X}=\mathrm{A}\left(\mathrm{T}_{\mathrm{o}}-\mathrm{T}_{\mathrm{s}}\right)
$$

Where $\mathrm{X}$ is the mol \% of impurity, $\mathrm{A}$ is the cryoscopic constant, $\mathrm{T}_{\mathrm{o}}$ is the freezing point of pure Glutaric acid and $\mathrm{T}_{\mathrm{s}}$ is the initial freezing point of the sample. The freezing temperature of the pure acid $T_{0}$ has been given the value $97.18^{\circ} \mathrm{C}$ as measured experimentally.

Table (3) gives the results of determinations of the liquidus temperature of Glutaric acid purified by the zone refining technique expressed as the electromotive force. These values have been corrected due to the thermocouple calibration. The freezing temperature of Gutaric acid sample after purification is $97.18^{\circ} \mathrm{C}$, from Raoult's formula (1) then, the estimated impurity content is 0.035 mol\% which means that the sample purity has increased to $99.965 \%$.

\section{Results and discussion:}

For the study of the freezing point of Glutaric acid, two cells were used, the bigger one filled with pure Glutaric acid and the smaller filled with commercial Glutaric acid (of purity $99.0 \%$ as given in by ALDRICH Co. Lot No. G 340-7).

Five runs were carried out after purification while for the commercial sample four runs were carried out. The results are given in Tables (1\&2) respectively.

Table (1): Results of the Glutaric acid freezing point after purification

\begin{tabular}{|c|c|c|c|}
\hline Date & $\begin{array}{c}\text { EMF at the } \\
\text { Freezing point } \\
\mathrm{E} \mu \mathrm{V}\end{array}$ & $\begin{array}{c}\mathrm{t}_{90} \\
{ }^{\circ} \mathrm{C}\end{array}$ & $\begin{array}{c}\text { Plateau } \\
\text { Duration } \\
\text { min. }\end{array}$ \\
\hline $15 / 03 / 96$ & 4129.80 & 97.18 & 120 \\
$18 / 03 / 96$ & 4130.50 & 97.19 & 90 \\
$19 / 03 / 96$ & 4129.90 & 97.18 & 105 \\
$20 / 03 / 96$ & 4129.80 & 97.18 & 145 \\
$21 / 03 / 96$ & 4129.80 & 97.18 & 130 \\
\hline
\end{tabular}

Table (2): Results of the glutaric acid freezing point before purification

\begin{tabular}{|c|c|c|c|}
\hline Date & $\begin{array}{c}\text { EMF at the } \\
\text { Freezing point } \mathrm{E} \mu \mathrm{V}\end{array}$ & $\begin{array}{c}\mathrm{t}_{90} \\
{ }^{\circ} \mathrm{C}\end{array}$ & $\begin{array}{c}\text { Plateau } \\
\text { Duration min. }\end{array}$ \\
\hline $01 / 07 / 96$ & 4129.20 & 97.16 & 95 \\
$03 / 07 / 96$ & 4131.00 & 97.20 & 90 \\
$07 / 07 / 96$ & 4132.90 & 97.23 & 80 \\
$09 / 07 / 96$ & 4132.00 & 97.23 & 85 \\
\hline
\end{tabular}


Table (3): Glutaric acid: melting points steps

\begin{tabular}{|c|c|c|}
\hline $\begin{array}{c}\text { Melted } \\
\%\end{array}$ & $1 / \mathrm{F}$ & $\begin{array}{c}\text { Melting value } \\
\mu \mathrm{V}\end{array}$ \\
\hline 25 & 4 & 4127.9 \\
50 & 2 & 4129.8 \\
75 & 1.34 & 4130.7 \\
\hline
\end{tabular}

Thermal analysis of high purity metals by careful inter-comparison of the plateau freezing temperature can give a good measure for discrimination between samples of different purity as shown in Figure. (3).

For that purpose, interest lies primarily on the form of the freezing curves and not on the freezing temperature. Figure (2) shows a typical freezing curve for two different Glutaric acid samples, recorded under similar conditions. Curve (1) for the Glutaric acid after (triple) distillation. Curve (2) for the commercial Glutaric acid of purity $99 \%$;

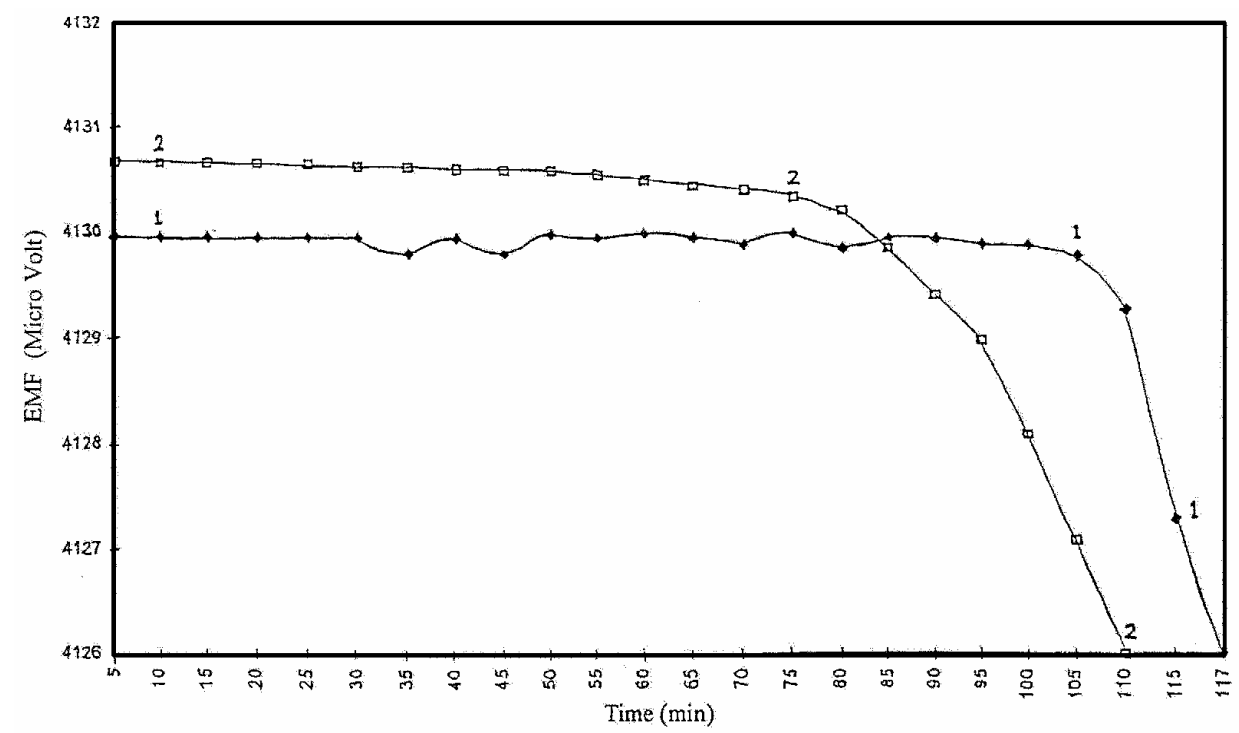

Fig. (2): Comparison between pure and commercial sample freezing curves.

From these curves the following can be seen:

The triple distilled Glutaric acid has the lowest (freezing) range and the most steady freezing plateau than in curve (2) for the commercial sample.

The existence of plateau of constant temperature on the cooling curves is due to the finite limit of about $0.020^{\circ} \mathrm{C}$ in temperature resolution that is usually obtainable in precision thermocouple type-T with nanovoltmeter. 
The rounding at the end of the freezing curve of Glutaric acid before purification is less sharp than that of curve (1) for Glutaric acid after purification, which is also a criterion of its higher purity than that of commercial one. This change in the slope near the end of freezing curve is due to the fact that, near the end of the freezing, most of the impurity has been redially swept to the molten region of the ingot. The molten region is close to the thermocouple and start to depress the temperature more rapidly. That is why the slop at the end of the freezing curve is a good measure of the impurity concentration in the original sample.

\section{Conclusion:}

High purity Glutaric acid could be obtained by zone refining technique.

Glutaric acid is adequately stable enough to be used as a reference point for calibration of thermometers in a temperature near $100^{\circ} \mathrm{C}$.

The freezing temperature was found to be $97.18 \pm 0.28 \mathrm{oC}$ for the purified sample of purity $99.99 \%$ and $97.23 \pm 0.28$ oC for the sample of purity $99.0 \%$.

\section{Acknowledgment:}

The author like to acknowledge the continued encouragement and willing help given by Prof. Dr. M.M. Ammar Professor of physics, NIS, during the progress of this work. Thanks also to Prof. Dr. N.I.El-Sayed head of thermometry department ( NIS- Egypt ) for her help .

\section{References:}

1. NIST, National Institute for Standards and Tecnology "The calibration of thermocouple and thermocouple material", 250-35, (1989).

2. H Preston-Thomas, Metrologia, 27, p 3 and 107 (1990).

3. N.I. El-Sayed, Ind. J. of Tech., 25, 28, (1967).

4. W.G. Pfann, Zone melting Instruments and technique, Science, 135, 1101, (1962).

5. Manual book of Degasa Zone Refining Apparatus (model 136000).

6. Scwob, F.W. and Wichers E., J. Res. National Standards, 25, 747, (1945). 